\title{
What is the Gaming Lifestyle?
}

\author{
An exploratory investigation
}

\author{
Matheus José Machado Dutra \\ Escola Superior de Propaganda e Marketing \\ Independent Researcher \\ Porto Alegre, Brazil \\ matheusjmdutra@gmail.com
}

\begin{abstract}
In marketing and the sociology of the digital world, a central research issue is how lifestyles are affected by virtual experiences. This research explores the topic of lifestyle a collective phenomenon that treats consumption patterns as forms of group expression - in the ambit of gaming. A total of 711 valid respondents from 67 countries took part in a questionnaire designed to gather information about the Gaming Lifestyle (GLS). The objective was to identify what game-related practices, habits, attitudes, and beliefs characterized this way of living. The exploratory factor analysis was employed to uncover underlying factors that could answer this question. Results pointed that Six Factors influence the GLS: competition, media, microtransactions, marketing and communication, socialization, and enjoyment. This paper contributes to the field of game studies by deepening our understanding of how gamers are impacted by in-game and out-game daily experiences.
\end{abstract}

Keywords—lifestyle; gamer; consumption; identity;

\section{INTRODUCTION}

The gaming lifestyle is not an obscure way of living anymore. It has become an accepted manner of conducting life for a specific group of individuals with its own set of characteristics and behavioral patterns. The gamer distinguishes from others by living in the frontiers of virtuality and reality as his activities, interests, opinions, and attitudes are affected by his experience in both realms [25], [58]. What defines a gamer is the sum of his interactions with his surroundings as he is susceptible to both the influence of his in-game presence and his out-game typical routine.

With the increasing number of active players, virtual worlds' populations count with many types of participants with different profiles, preferences, and goals [4], [20], [44]. Thus it is expected that with the inclusion of a myriad of new players, styles, and technology, the nature of factors that affect the gaming lifestyle also have changed over the years [4], [29], [34], [53]. Some of these lifestyle components the literature has already scrutinized, nonetheless with the everchanging virtual environment, it is only natural to assume that novel influences may affect the new batch of gamers.

For this article, the objective is to organize a concept of Gaming Lifestyle (GLS) based on online gaming behavior and out-game factors of influence such as streaming, social media activity, and marketing initiatives [39], [47], [58], [59]. The idea of the GLS is to portray the universe of practices that constitute the life of a gamer. However, as an exploratory research, this study can be appraised as an initial effort to map and comprehend gaming lifestyle factors. Furthermore, this paper presents six factors associated with in-game and outgame player behavior that will aid in the development of better notions about this way of living. Therefore, this paper answers the following question:

- What gaming related practices and attitudes characterize the gaming lifestyle?

Since many of the constituents of the gaming lifestyle are still indefinite or vague, a scale was developed, and 711 respondents from 67 countries participated in an online global survey. The goal of the questionnaire was to assess the participants' perception of lifestyle topics associated with gaming. As for the statistical analysis, the employment of the exploratory factor analysis was to uncover a set of underlying factors and appoint latent constructs.

\section{THEORETICAL FRAMEWORK}

\section{A. The Gaming Lifestyle}

The concept of lifestyle can be described as a group phenomenon in which groups of individuals consistently share a set of beliefs, display specific behaviors, and express themselves similarly to other members of the party [34]. The lifestyle is a multicultural media-influenced way of living based on characteristical consuming habits manifested in different social scenarios [3], [14]. Those peculiarities, in effect, distinguish gamers from other groups and concurrently define them as a body. Moreover, it creates behavioral patterns for individuals to follow and fit in.

In order to understand the reality of modern gamers, in this paper, the gaming lifestyle is examined as an alternative way to look at the behavior of players, considering them a hybrid consumer category, which exists in both the offline and online arenas, and which has peculiar social idiosyncrasies that differentiate them from other digital subcultures [10], [20], [26]. This study encourages people to take a look at how the gaming lifestyle induces consumption and how consumption defines this way of life [3], [34]. 
The term lifestyle suggests that repeated and related attitudes, behaviors, interactions, and cognitive patterns between members of a social group exist and are perceivable. In marketing, this understanding is fixed and can be observed, mainly from the perspective of consumption, whether it is economic, social, cultural, symbolic, or through media, and it is the main structure for producing a technical set that can explain and can predict how a subject spends their money, time and differentiates themselves from others [3], [34]. Gamers have emblematic characteristics when analyzed from the consumption standpoint [6], [8], [9], [12, [13], [16], [54]. For this reason, there are specific criteria to their social stratification and consequent market segmentation, which means that it is necessary to look for other parameters to conduct a proper analysis of their lifestyle [20], [29], [34], [55].

It is valuable to debate that the notion of lifestyle, including in the ambit of gaming, can be contemplated from a broad spectrum of views. From the personalities/values approach, one would assume that the gaming lifestyle conceptualizes around the virtual and tangible social patterning of consumption, once consumption represents a manifestation of shared behavioral and attitudinal models. Conversely, from the object signification perspective, objects (virtual or tangible possessions) are perceived as receptacles to which different groups of people attribute meaning. Through this viewpoint, individuals believe that the objects they consume are embedded with transcendental significance [8].

Both approaches work as forms of collective expression through consumption. In this sense, lifestyles surge from relational differences between consumption patterns existing within symbolic boundaries. Lifestyles serve as a basis for affiliating with specific categories of individuals and, likewise, as a means for differentiating oneself from others, consolidating social positions [34]. Thereby, in light of the lifestyle theory, it is possible to distinguish gamers from other categories of consumers, and at the same time, group players with similar consumption standards.

\section{METHODOLOGY}

This section presents what statistical procedures were employed to assess the sample's perception about gamingrelated activities that characterize their lifestyle [5]. Considering this study investigates a phenomenon with multiple variables, the employment of the Exploratory Factor Analysis aimed to reduce the number of elements analyzed [40]. The Cronbach's Alpha coefficient was applied to determine the degree of reliability and validity of the questionnaire [2]. The Kayser-Meyer-Olkim method and Bartlett's sphericity test intended to confirm whether the Exploratory Factor Analysis was an adequate test [40]. The total variance indicated the proportion to which each factor explains the event [2]. Lastly, the factor loadings were a measure that ratifies the degree of importance of each construct to each factor associated [5].

\section{A. Sample and Data Collection}

1.208 people answered the survey from 67 countries. 711 of which were validated as they met the stated requirements. The selection criteria included taking an active part in games and online gaming communities, as well as having made microtransactions or micropayments for games of any kind over a period of no less than 12 months. Those who did not apply to were discarded.

Data was collected from the Reddit platform through public posts. More specifically, from subforums aimed at online games of different genres, provided that they were competitive, multiplayer, and sold skins. Every post presented an introductory note written exclusively for each sub-forum so players could relate to the research topic and feel more engaged.

Participation was voluntary, and the questionnaire was active for two weeks, from May 1st of 2019 until the 15th of the same month. It was a global survey, and $44.62 \%$ of the sample were American players, $8.03 \%$ British, 5.96\% German, $4.80 \%$ Canadian, and $4.55 \%$ Brazilian. Those were the top five countries with the most significant share in the sample. Among the participants, $84 \%$ identified themselves as male, $14.21 \%$ female, and $3.09 \%$ as others.

With regard to age, the highest concentrations were in the age groups 18 to 23 years $(38.26 \%)$ and 24 to 29 years (29.68\%), which, when added up, corresponded to $67.94 \%$ of the entire sample. Concerning the education level, most respondents were in or had completed higher education $56.54 \%$ of the sample group. After this, came those who had recently finished high school and were not enrolled in higher education courses $(15.75 \%)$.

As for the sample playing habits, the following tables (Tables I to IV) summarizes a set of data that includes preferred days of the week to play, gaming session duration, and perceived level of engagement. This way, it is possible to portray a more matching characterization of the gamers.

TABLE I. PREFERRED DAYS OF THE WEEK TO PlAY

\begin{tabular}{|l|c|c|}
\hline Item & $\mathbf{N = 7 1 1}$ & \% \\
\hline Monday & 92 & 12.9 \\
\hline Tuesday & 92 & 13 \\
\hline Wednesday & 94 & 13.15 \\
\hline Thursday & 94 & 13.26 \\
\hline Friday & 110 & 15.50 \\
\hline Saturday & 112 & 15.7 \\
\hline Sunday & 117 & 16.39 \\
\hline
\end{tabular}

It is possible to perceive an even result when it comes to preferred days of the week to play. The largest percentage of 
the sample opted to play on the weekends - $16.39 \%$ on Sundays, followed by $15.7 \%$ on Saturdays and $15.5 \%$ on Fridays. Since there was not too much of a difference in the results, it is possible to infer that the sample was very committed to gaming practices and is capable of maintaining a fair frequency throughout the week. For some, gaming must be a well-established habit.

TABLE II.

PLAYING TIME PER SESSION

\begin{tabular}{|l|c|c|}
\hline Item & $\mathbf{N = 7 1 1}$ & \% \\
\hline Less than one hour & 22 & 3.1 \\
\hline One to two hours & 237 & 33.3 \\
\hline Three to four hours & 286 & 40.2 \\
\hline Five to six hours & 107 & 15.1 \\
\hline More than seven hours & 59 & 8.4 \\
\hline
\end{tabular}

Regarding playing time per session, $40.2 \%$ of the participants claimed to play from three to four hours each session, $33.3 \%$ from one to two hours, and $15.1 \%$ from five to six hours. It is safe to assume that for these respondents, gaming is an engaging and immersive activity worth spending a few hours each time they play.

TABLE III.

USUALLY PLAY:

\begin{tabular}{|l|c|c|}
\hline Item & $\mathbf{N = 7 1 1}$ & \% \\
\hline Solo & 363 & 51.07 \\
& & \\
\hline With friends or Teammates & 348 & 48.93 \\
& & \\
\hline
\end{tabular}

$51.07 \%$ of the sample opts for playing solo against $48.93 \%$ who prefer playing with teammates or friends.

TABLE IV. SELF-PERCEIVED LEVEL OF ENGAGEMENT

\begin{tabular}{|l|c|c|}
\hline Item & $\mathbf{N = 7 1 1}$ & \% \\
\hline Hardcore Gamer & 162 & 22.78 \\
\hline Avid Gamer & 413 & 58.09 \\
\hline Casual Gamer & 122 & 17.16 \\
\hline Sporadic Gamer & 14 & 1.97 \\
\hline
\end{tabular}

When asked what kind of gamers the participants perceived themselves to be, $22.78 \%$ believed being hardcore gamers, $58.09 \%$ avid gamers, $17.16 \%$ casual gamers, and $1.97 \%$ sporadic gamers. Those numbers suggest the degree of perceived commitment and dedication to gaming practices of the participants. This commitment typically translates into gaming habits such as viewing live streams, eSports, active or passive participation in gaming communities, sharing gamerelated content in social media, time invested into playing sessions, and improving game-related skills. The following sequence of tables (Tables V to VII) displays some consumption characteristics of the participants.

TABLE V. EVER MADE MiCROTRANSACTIONS

\begin{tabular}{|l|c|c|}
\hline Item & N=711 & \% \\
\hline Yes & 563 & 79.25 \\
\hline No & 148 & 20.75 \\
& & \\
\hline
\end{tabular}

When asked if they ever bought virtual assets with real currency, $79.25 \%$ of the sample confirmed making microtransactions, against $20.75 \%$ who did not invest real currency in in-game purchases.

TABLE VI. MONTHLY SPENDING IN MICROTRANSACTIONS (USD)

\begin{tabular}{|l|c|c|}
\hline Item & $\mathbf{N = 7 1 1}$ & \% \\
\hline Monday & Don't spend money & 32.9 \\
\hline Tuesday & 1 to 10 & 44.2 \\
\hline Wednesday & 11 to 20 & 12 \\
\hline Thursday & 21 to 30 & 4.6 \\
\hline Friday & 31 to 40 & 1.6 \\
\hline Saturday & 41 to 50 & 1.8 \\
\hline Sunday & 51 or more & 3.0 \\
\hline
\end{tabular}

Curiously enough, $32.9 \%$ of the respondents claimed not spending monthly on microtransactions which possibly means that they make in-game purchases irregularly or sporadically. $44.2 \%$ spend from one to ten USD monthly, $12 \%$ from 11 to 20 USD, $4.6 \%$ from 21 to 30 USD, $1.6 \%$ from 31 to 40 USD, $18 \%$ from 41 to 50 USD and a slight rise to $3 \%$ for 51 or more USD.

TABLE VII. PREFERRED VIRTUAL ASSET For Purchase

\begin{tabular}{|l|c|c|}
\hline Item & N=711 & \% \\
\hline Characters & 178 & 18.1 \\
\hline Weapons or guns & 47 & 12.8 \\
\hline New scenarios or levels & 126 & 7.5 \\
\hline New chapters & 74 & 2.8 \\
\hline New gaming modes & 28 & 42.3 \\
\hline Skins & 416 & 0.7 \\
\hline Emotes & 7 & 0.4 \\
\hline Icons & 4 & \\
\hline
\end{tabular}




\begin{tabular}{|l|c|c|}
\hline Pets & 9 & 0.9 \\
\hline Frames & 4 & 0.4 \\
\hline Boosters & 22 & 2.2 \\
\hline Others & 68 & 6.9 \\
\hline
\end{tabular}

Regarding the acquisition of new virtual goods, players displayed varied tastes. Yet, $42.3 \%$ of the participants answered that they prefer buying skins, $18.1 \%$ stated that they would pick new characters, $12.8 \%$ favor the purchase of new scenarios or levels, while $7.5 \%$ prefer buying new scenarios, and $6.5 \%$ would opt for other not listed virtual products.

\section{B. Materials}

The questionnaire was designed to collect information about factors related to the gaming lifestyle, the sample's perception about specific topics, and evaluate their attitudes. The questions were created using the Likert Scale. It was a scale composed of a set of items, and each item represented an idea related to gaming, consumption, and routine [60]. The subjects were asked to express their degree of agreement or disagreement from a range of seven points.

Only closed questions were used so that the statistical method could be applied directly. The questionnaire was considered reasonable and easy to complete - a total of 69 questions, eight of which were about habits, three about demography, and one about what type of gamer the respondents considered themselves to be. The questionnaire was initially created in North American English and later translated into Brazilian Portuguese and Spanish.

The survey questions were grouped by theme. Each theme represented a construct that, according to literature, affects lifestyle, in-game behavior, and the players' purchase intention. There were six different topics: in-game performance and competition, enjoyment, socialization and interaction, marketing and communication, streaming and media, and microtransactions [9], [12], [13], [37], [54]. Each question assembled aimed to answer, in its scope, how involved with the gaming lifestyle the players were - with emphasis on consumption.

\section{Design}

To unravel latent variables associated with the gaming lifestyle, the Exploratory Factor Analysis (EFA) is a multivariate statistical method capable of distinguishing and identifying the theoretical fundaments and hypothetical constructs that may explain the order and structure of the assessed variables [40]. Briefly, the EFA searches for variables that strongly correlate with each other in a group but correlate poorly with external variables. These sequences and groups of intercorrelations respond for factors [2].

However, to employ the EFA, effectively there are some guidelines that one should mind. For instance, all variables must be measured in an interval level or ratio scale; [40] suggests 10 to 15 subjects per variable to better reproduce population values, and variables should be reasonably intercorrelated. Naturally, there are more guidelines that one should attain. Nonetheless, since this is an exploratory investigation, other statistical procedures were employed to ensure the validity, reliability, and suitability of the EFA method to the sample [60].

The first one is the Cronbach's Alpha measures the internal consistency of a scale and expresses between 0 and 1 the degree of internal consistency. The internal consistency indicates to what extent the items in a test measure the concept or construct they intend [60]. The second is the Kaiser-MeyerOlkin (KMO) which was used to determine the appropriateness of the data for the factor analysis [40]. The KMO evaluates the variance proportion amongst all the variables tested [5]. The closer the result is to 1 better [2]. Values below 0.5 are unacceptable [2].

The Bartlett's test of sphericity measures how strong is the correlation between variables. A significant result of less than 0.05 indicates that the statistics are acceptable for further analysis [40]. As for the factor extraction method of the EFA, the choice was the principal components analysis (PCA). A factor extraction is a dimensionality reduction technique commonly used to turn large data sets into small clusters of variables while still capturing the most relevant aspects of the topic in question [45].

The main concern revolving around the EFA and the PCA is that the EFA aims to uncover latent or unobserved constructs, while the PCA is dedicated to mathematically extracting a small but representative amount of data from larger clusters of information [45]. It is worth mentioning that the EFA seeks to comprehend the interconnection among variables and not merely derive fewer variables.

The EFA is altogether a baseline tool in the development of hypothetical constructs and validation of behavioral theories and psychological measurement instruments. It reveals inconspicuous commonly shared characteristics of people manifested through interpretative scores and translated into empirical phenomena. The benefit of the literature review is to support theoretical claims and connect obtained results with verified concepts from other authors [45].

\section{RESULTS}

Coming next, the results of the Exploratory Factor Analysis, as well as descriptions of each factor and the factor loadings of each construct that makes up each factor.

\section{A. The Six Factors}

The six influencing factors represent constructs of interest, and each expresses different in-game or out-of-game behavior of players. The assumption is that these six dimensions can predict, with a sufficient degree of accuracy, how engaged with the gaming lifestyle the player perceives himself to be and how each of the six components affect his personal world.

These factors derive from the constructs evaluated in the questionnaire. They were selected based on the statistical 
application of the Reliability test designed to verify the stability of the outcome, their internal reliability, and to check the constructs measured using the scale [60]. The considered ideal range for alpha values is between 0.7 and 0.9 [2]. Consequently, only six of the scaled elements proved to be compatible. Table VIII introduces the six factors.

TABLE VIII. STATISTICS ON THE RELIABILITY OF THE SiX FACTORS

\begin{tabular}{|l|c|}
\hline Component & Cronbach's Alpha \\
\hline Challenger Factor & 0.831 \\
\hline Media Factor & 0.886 \\
\hline Transactional Factor & 0.797 \\
\hline Marketing Communication Factor & 0.833 \\
\hline Social Factor & 0.867 \\
\hline Enjoyment Factor & 0.709 \\
\hline
\end{tabular}

Each of these factors is supported by specific literature. Reference [50] and [54] identified perceived enjoyment, character competency, goal orientation, social influence, and real currency availability as relevant motivations for purchases in virtual worlds. Reference [12] believe that enjoyment, character competency, visual authority, and monetary values can appropriately explain the perceived value of in-game items, thus influencing purchase behavior. In the same line of thought, [30] presented social interaction, competition, and economic rationale as relevant purchase motives.

On the other hand, [13] noticed that in-game purchases could be facilitated if adopting other transactional methods. To fill this gap, the Transactional Factor examines the players' opinions regarding alternative payment options. Reference [13] also indicate a faint connection between brand presence and the player base. Therefore, the Marketing Communication Factor investigates if gamers are receptive to this type of commercial stimulus. Lastly, [37] and [57] suggests that game streaming viewing have an impact on in-game enjoyment, social interaction, and serves as a mean of information. The Media Factor is to clarify whether streaming media spectating does influence the gaming lifestyle and in-game behavior [38].

After confirming which factors seemed in compliance with the research scope, it was imperative to determine if the factor analysis was assuredly a tool that could satisfy the research goals. [45] recommends employing the Kaiser-Meyer-Olkin (KMO) sample adequacy measure and Bartlett's sphericity test to verify the appropriateness of the EFA. Tables IX and X shows the KMO and Bartlett's sphericity test results.

TABLE IX.

KMO TEST

\begin{tabular}{|l|c|}
\hline Kaiser-Meyer-Olkin Measure & 0.863 \\
\hline
\end{tabular}

The KMO adequacy index of the sample was 0.863 , which is considered an optimal variable according to [5].
TABLE $X$.

BARTLETT'S SPHERICITY TEST

\begin{tabular}{|l|l|c|}
\hline \multirow{3}{*}{ Bartlett's sphericity Test } & Approx. Chi-square. & 18253.231 \\
\cline { 2 - 3 } & DF & 1540 \\
\cline { 2 - 3 } & Sig. &, 000 \\
\hline
\end{tabular}

Bartlett's sphericity test values indicate a level of significance $(\mathrm{p}<0.05)$ which means that the matrix should be factored in order to reject the null hypothesis that the data matrix is similar to its identity matrix [2].

To obtain factorial components at the required level, it was essential to calculate the total variance between the variables. According to [5, pp. 212] the variance explained defines the "part of the common variance that a factor, or a combination of factors, can extract out of a given data set". When using the principal component method, the average variance explained is $66.325 \%$, a result that, as reported by [40], indicates a good level of variance. However, significant eigenvalues were only concentrated in the initial variables. Therefore, Table XI depicts the total variance of the first six items that define the six factors listed, adding up to $44.924 \%$ of the total variance. Naturally, this process was intended to discard data with only a minimal loss of information.

TABLE XI. TOTAL VARIANCE EXPLAINED

\begin{tabular}{|l|c|c|c|}
\hline \multirow{2}{*}{ Component } & \multirow{2}{*}{ Total } & \multicolumn{2}{|c|}{ Initial Eigenvalues } \\
\cline { 3 - 4 } & & $\begin{array}{c}\text { \% } \\
\text { variance }\end{array}$ & $\begin{array}{c}\text { \% } \\
\text { cumulative }\end{array}$ \\
\hline Challenger Factor & 9.819 & 17.535 & 17.535 \\
\hline Media Factor & 4.351 & 7.770 & 25.305 \\
\hline Transactional Factor & 3.336 & 5.956 & 31.261 \\
\hline Marketing Communication Factor & 2.951 & 5.270 & 36.531 \\
\hline Social Factor & 2.499 & 4.463 & 40.994 \\
\hline Enjoyment Factor & 2.200 & 3.929 & 44.924 \\
\hline
\end{tabular}

The fourth step for the selection of factors was the Principal Component Analysis, a vector orthogonalization technique. The idea is to convert a group of supposedly correlated variables into a set of linearly uncorrelated variable values [45]. In short, the principal component analysis broke down the original data into a set of linear data, while the varimax orthogonal rotation attributed values to the rotated matrix and identified the eigenvalues associated with each factor [45]. Only variables with factorial values equal to or greater than 0.50 were used from the rotated matrix. The following describes each factor and how they influence the gaming lifestyle.

\section{B. Challenger Factor}

The Challenger Factor addresses the concept of competition in its various forms. The ideas of advantage, rivalry, victory, success, and performance are a few of the primary elements that each player identifies with and a lifestyle focused on overcoming challenges. From a certain 
point of view, all gamers are competitive, to a greater or lesser extent or under specific circumstances [6], [11], [62].

TABLE XII. CHALLENGER FACTOR

\begin{tabular}{|c|c|}
\hline Construct & Factor Loading \\
\hline I am a competitive player & 0.800 \\
\hline Competing is a priority to me & 0.760 \\
\hline Competing makes me a better player & 0.721 \\
\hline $\begin{array}{l}\text { I want to be one of the best players in the game that } \\
\text { I play }\end{array}$ & 0.721 \\
\hline $\begin{array}{l}\text { I think it is good to have a competitive spirit in } \\
\text { gaming }\end{array}$ & 0.662 \\
\hline Winning is important to me & 0.660 \\
\hline $\begin{array}{l}\text { Success and accomplishments in gaming are } \\
\text { important to me }\end{array}$ & 0.642 \\
\hline High performance in gaming makes me happy & 0.632 \\
\hline $\begin{array}{l}\text { I would rather have fun playing than winning } \\
\text { matches }\end{array}$ & -0.507 \\
\hline
\end{tabular}

The principal expression of competition in online competitive games is the PVP (Player versus Player) interaction. It is characterized by direct conflict or violent combat between characters or avatars controlled by players [30], [62]. This competitive system creates a dual environment where exist winners and losers, successes and failures, competence and incompetence. The outcome of the matches will determine the degree of satisfaction and dissatisfaction, enjoyment and anguish, and pride and shame [50]. The type of player who is impacted by this factor is the one who is looking to experience those human feelings and exhibit the desire to prove oneself to others - that makes competitive games attractive to the public.

It is worth remembering that such competition is social. It can exist between teams or individuals. As a result, the Challenger Factor also encourages socialization, cooperation, and consumption [29], [12], [50], [62]. This sort of consumption is motivated by the desire for recognition, demonstration of power, or to gain a competitive advantage over other players. Those who are influenced by this factor tend to consume content that helps to improve their in-game performance [38]. Therefore, some of the most sought-after lifestyle topics are replays of matches from the best players, live championships, tutorials, and in-depth analysis of game dynamics [6], [37].

\section{Media Factor}

The Media Factor is one of the six that explicitly impacts in-game social behavior and the gaming lifestyle [3], [29], [34]. It is the main factor responsible for explaining the wideranging effect of the mediatic consumption of gaming-related products [10], [36]. Among the constructs that characterize this factor, themes such as the popularization and dissemination of slang and expressions, identification, group identity, spectating, and escapism deserve an underline.
TABLE XIII.

MEDIA FACTOR

\begin{tabular}{|l|c|}
\hline Construct & Factor Loading \\
\hline I have fun with gameplay streams & 0.890 \\
\hline I enjoy watching game streaming & 0.839 \\
\hline $\begin{array}{l}\text { I prefer watching game streaming to other television } \\
\text { programs }\end{array}$ & 0.777 \\
\hline \begin{tabular}{l} 
I learn from gameplay streams \\
\hline I like entertaining streamers \\
streamers I love
\end{tabular} & 0.766 \\
\hline $\begin{array}{l}\text { I like to watch the best players streaming } \\
\text { gameplay itself }\end{array}$ & 0.559 \\
\hline \begin{tabular}{l} 
I think the streamer is more important than the \\
\hline
\end{tabular} & 0.536 \\
\hline
\end{tabular}

The media component can be appreciated by a broad range of angles. With that in mind, the guiding line of thought points that the mediatic environment exerts great control in public opinion, global agenda, individual self-perception, and as a consequence, the lifestyle of groups of individuals [14], [34], [39]. In the gaming reality, the media has a significant role in determining what makes a gamer a cyberspace subculture and not a group of solitary subjects who spend the whole night until dawn in front of a screen smashing the keyboard [20], [23], [44].

The development of the gamer identity is greatly supported by the existence of gregarious gaming communities, which encourage its populace to cultivate feelings of loyalty and belonging. More than that, those communities represent a profuse ambient where individuals can freely express themselves and find resonance with fresh ideas [19].

In the cyberspace, this kind of association is vital to the emergence of new promising trends capable of transcending the virtual space. In truth, the gaming lifestyle could only be established due to the maturity of its people and the evolvement of the mediatic setting [19]. The gaming scene, partially, was only popularized as a product of the protoindustry of social media entertainment in which any person may be fit to become its own show presenter and protagonist [10], [36], [39] [43], [59].

Similar to traditional media models, streamers and social media performers influence their audience with the cognate principles of mass communication [43]. Nowadays, these social media pseudo-celebrities are responsible for what is called the economy of attention [59]. It is a recent theory of mass communication that describes the rising importance of attention capital and how information and entertainment gave birth to a mental capitalism characterized by the value given to attention in place of other forms of capital [24].

Streaming channels, when treated as a form of mass media, can form opinions and create a more pluralistic and democratic online environment; so that the streamer, due to their proximity to the community, becomes both a 
Vol. 06, No. 02, 2021

spokesperson and a model to be followed [19], [57]. On the other hand, the whole relationship as a spectator, albeit as interactive as current technology has made this experience, is still a parasocial relationship wherein the viewer is watching a mediatic persona created especially for an online live performance [46], [59].

In fact, no stream is successful unless it can create and put into practice three concepts: identification - the viewer needs to see a little of themselves in the streamer -, projection - the viewer yearns to see whom he would like to be or establish an idealized relationship with the streamer - and presence - the streamer must be part of the lives of the audience on different screens or social media. This way, a content creator may influence gamer groups, their in-game and out-of-game consumption, create new fashions and develop as part of the entertainment industry [38], [46], [59].

This subject could be contemplated as a new movement of global media cultural expansion, colonized by brands and corporations commanding the attention economy [24], [22], [48]. This remarkable novelty of modern times is not limited to the gaming industry. It is a widespread phenomenon across all sectors that influence consumption patterns and public opinion [19], [14] [39]. So, many of the distinctive characteristics of a lifestyle for gamers and consumption trends are substantially defined by those on top of the social media network - the ones with more attention income [19], [24], [34], [43].

Finally, it is possible to compare the public's expectations in streams and eSports with the spectacle of gladiators in Rome, principally because of the vicariousness phenomenon, in which the viewer believes that the streamer is fighting for them [31]. Even so, many gamers prefer to watch streams than play.

\section{Transactional Factor}

Transactional Factor deals with microtransactions (MTX), a business model in which players can make purchases through micropayments, and Real Money Trading (RMT) which, is defined as the act of using real money when purchasing virtual goods, for example, skins, characters or ingame currency. Both are related to one of the main influences on the purchase decision: the perceived value, [9]. In several studies, the economic component had a positive effect and a high impact on the behavior of consumers [3], [4].

TABLE XIV. TRANSACTIONAL FACTOR

\begin{tabular}{|l|l|}
\hline Construct & Factor Loading \\
\hline
\end{tabular}

\begin{tabular}{|l|c|}
\hline $\begin{array}{l}\text { I tend to make in-game purchases with real money } \\
\text { with a degree of regularity }\end{array}$ & 0.794 \\
\hline $\begin{array}{l}\text { If it was possible I would purchase in-game goods } \\
\text { by deferred payment }\end{array}$ & 0.789 \\
\hline I enjoy buying in-game goods & 0.763 \\
\hline I tend to acquire in-game goods whenever I feel like & 0.757 \\
\hline $\begin{array}{l}\text { If it was possible I would purchase in-game goods in } \\
\text { installments }\end{array}$ & 0.730 \\
\hline
\end{tabular}

Microtransactions and RMT became popular revenue generation strategies for game developers and publishers [35]. In fact, the future of the gaming industry is to provide gaming as a service and, over time, improve all the monetary models so that the game design is inherently prepared to turn the gaming experience into a native revenue stream [61].

While the gaming industry sees this transition as the future, the gaming community does not fully support it as it could convert gaming into a fragmented adventure in which an individual has to buy more and more to progress in the game and live the entire experience. Other side effects related to the microtransactions are the pay-to-win controversy and gambling-associated behavior, which are considered potentially detrimental to the consumer and the community [17].

Anyhow, the idea behind this factor is to expand the purchasing processes. Contemporary monetization strategies have proven popular and spread to many different gaming genres and platforms. Nonetheless, advancements in payment technology stimulated the emergence of new types of payment methods [17].

The addition of alternative payment processes could potentially affect consumers' buying behavior in in-game markets [4]. Furthermore, the proposed methods are prevalent in Brazil and a valid option for other regions as well. They may stimulate the acquisition of virtual goods by impulse purchases.

They are installments payments and deferred payments. Payment by installments is the same as dividing the total amount into equal parts and paying them over the course of months, defined on the invoice date and subject to taxation in accordance with local legislation, current economic policy, or financial institution [56]. A deferred term is where the amount to be paid only begins to be debited from the buyer's account at a previously agreed future schedule and can be paid in installments or not [42].

The inclusion of such systems intends to make it easier for players to acquire desirable goods and improve acceptance or adoption rates for microtransactions [35]. Many players use those systems to leverage advantages over their competitors, unlock customization options for avatars and weapons, obtain new characters or scenarios, or enjoy expandable new content [13], [14], [30]. Simplifying the purchasing process and facilitating access to credit will surely encourage players to make even more purchases. It is worth remembering that a 
noticeable characteristic of the contemporary gamer is to make in-game purchases, especially the most committed ones. Nowadays, microtransactions play a big part in the player's world.

\section{E. Marketing Communication Factor}

The Marketing Communication Factor observes the relationship between gamers and promotional communication and marketing in the gaming market. Since gaming became a popular leisure activity for many people, it is only natural to assume that the manner brands communicate and relate to customers may have changed, especially in the ever-changing virtual world [15], [22], [63].

TABLE XV MARKETING COMMUNICATION FACTOR

\begin{tabular}{|l|c|}
\hline Construct & Factor Loading \\
\hline $\begin{array}{l}\text { I prefer gaming advertising to other types of } \\
\text { publicity and marketing promotion }\end{array}$ & 0.818 \\
\hline I believe gaming advertising is above average & 0.815 \\
\hline Gaming advertising always captures my attention & 0.793 \\
\hline I think gaming advertising campaigns are amusing & 0.775 \\
\hline I do not think gaming advertising is nocive & 0.547 \\
\hline
\end{tabular}

[13] Noticed that there was a lack of studies on the influence of marketing and communication strategies on purchase intent of virtual goods and lifestyle in the gaming context. In this sense, some topics may still be hazy. Despite this, advertising and publicity agencies have identified the virtual environment of online games as a representation or simulation of reality and, thus, a potential new media vehicle for advertising [7], [15], [26]. At this point, video games are no longer untouched ecosystems, totally focused on leisure. They become commercial vehicles and communication media [43], [48].

According to [63], advertising techniques are more effective in online and offline video games than other media channels. As a matter of fact, advertising campaigns about video games and associated brands do not tend to receive significant rejection as can happen with other products and services. [32] Believe that consumers appreciate gaming publicity and are even attracted to them. In cases, players actively participate and enjoy promotional campaigns.

The brands' advertisement activities surrounded players and compelled them to what can be called commercial immersion. This phenomenon resulted in the gamer population being able to experience brand content on multiple screens almost all day long, whether they enjoy it or not [7], [39]. Techniques such as brand placement and product placement are examples of what marketing professionals utilize to improve brand awareness, brand exposure and to increase sales of particular products, even in the virtual environment [10], [49].

For the gaming lifestyle, commercial initiatives weigh heavy on its development since consumption and lifestyle are inherently connected [55]. Nevertheless, so games do not turn themselves into simply publicity vehicles, announcement companies must adjust their marketing strategies, and developers should adapt the game design to a model that inherently promotes immersive, interactive, optional, and nonobstructive commercial content [10], [22], [32].

Otherwise, marketing initiatives could be perceived as detrimental to the experience itself. When done consciously, punctual modifications may turn the in-game advertisement and brand imagery into healthier affairs, pleasing both the gamer community and business companies [22], [32].

\section{F. Social Factor}

Social constructs are chief predictors of players' choices and actions. These constructs exist as a result of human interaction and interpersonal influences [28], [29]. Behavior, identity, culture, and consumption are some of the topics associated with Social Factor. Nevertheless, in the gaming environment, socialization is, in a certain way, anomalous, as it can only be truly understood when you look at its two sides: in-game and out-of-game socialization.

\section{TABLE XVI. SOCIAL FACTOR}

\begin{tabular}{|l|c|}
\hline Construct & Factor Loading \\
\hline I am interested in socializing with other players & 0.865 \\
\hline $\begin{array}{l}\text { I think establishing meaningful relationships with } \\
\text { other players is a relevant process }\end{array}$ & 0.835 \\
\hline I like to chat with other players & 0.828 \\
\hline
\end{tabular}

The social realm, in the virtual world, can be observed from different perspectives. The first is about social interaction and how the players coexist together and in intimate social groups [27]. The second analyzes language and communication in virtual environments - slangs, expressions, and proper terminology [16]. The third is to look at social perception and how players, avatars, and characters distinguish themselves and express the gamer's individuality [47]. The fourth deals with types of social organization, social stratification, and how social layers are created [28]. The fifth one is about the importance of the game design in social dynamics [30].

Despite everything, the Social Factor is a rather curious component within the gaming lifestyle concept, much by virtue of the identification process. As complex as it is, the identification process can be thought of as the association, social cognition, and symbolic interaction between social structures and the individual self [18]. In less complicated terms, one's identity is constituted of cultural, political, economic, social, and individual imprints that lead to behavioral and attitudinal patterns. The subject is, to a certain level, responsible for the construction, maintenance, and adjustment of personal identities.

[8] comprehends that a subject's cognitive schema and perception are highly organized and developed by groups and 
Vol. 06, No. 02, 2021

social life. Hence, the capability of one's identification occurs due to social interaction. In virtual worlds, it is understood that this social theory manifests itself, essentially, this way: the player is introjected with existing values that are disseminated in-game through interaction with other players and the game itself [1], [52]. Consequently, players adopt habits, attitudes, forms of expression, and beliefs shared in virtual environments. Such players are described to live their gaming moments so intensively and vividly that they end up bringing part of their experience to their out-game lives [21], [47].

The proposition of a social theory applied to the gaming lifestyle stems from the idea that a collective phenomenon, such as the gamer identity, cannot be accurately explained from an individual framework alone [8]. The gamer identity is, at the same time, an internal process in which a player's self-identity is influenced by the game life and by the tangible reality; and a group construction psychologically developed if a congregation of people unites and relate in terms of shared beliefs, values, behavioral patterns and consumption habits [8], [20], [53].

Therefore, for the existence of a gamer identity and a gaming lifestyle, there, necessarily, should be an organized amount of individuals with similar self-perceptions and willingness to assemble [20], [21]. Under this influence, the player gradually embraces certain behavioral elements to its cognitive repertoire and starts to showcase what could be called a gaming persona [1], [8], [18], [52]. The gaming persona can be considered the embodiment of in-game values that fosters online and offline identity integration.

Finally, the degree and quality of assimilation of values and behaviors incorporated from the virtual world experience are extensively affected by the level of engagement one has with the virtual and the gaming lifestyle [14], [52]. Commitment determines whether the gaming lifestyle and the gaming persona are no more than a brief passage in one's life narrative or a stable fragment of the self and part of the player's daily life.

\section{G. Enjoyment Factor}

The Enjoyment Factor is a very discussed and explored factor in the gaming literature. Authors such as [50], [51], [64] describe this feeling as being an intrinsic motivation related to their perception of pleasure, contentment, fun, and joy. [64] identified that this factor creates a sense of reward from the pleasure in undertaking the gaming activity and not because of any particular objective or expected result.

TABLE XVII. ENJOYMENT FACTOR

\begin{tabular}{|l|c|}
\hline Construct & Factor Loading \\
\hline Joy is an important feeling when I play games & 0.827 \\
\hline
\end{tabular}

\begin{tabular}{|l|c|}
\hline I try to have fun in each and every gaming session & 0.807 \\
\hline For me, gaming is a fun hobby & 0.618 \\
\hline Time flies by when I play games & 0.529 \\
\hline
\end{tabular}

What the Enjoyment Factor addresses, above all, is the basic human need to feel pleasure. Electronic games represent a pleasurable moment, an instant of joy amongst the challenges and burdens of a player's daily life [33]. More than that, games are entertaining and a great source of fun.

Enjoyment is a multifarious state that encompasses physiological, cognitive, emotional, and social elements [64]. Enjoyment in games does not exist by itself. It is the product of a player's experience in virtual worlds and is correlated with the perceived challenge, fluid gameplay, the difference in skill between players, social interaction, and immersive narrative [41], [50].

There are many views on the subject of enjoyment. Nonetheless, a fair share of them seems to relate enjoyment to the satisfaction of needs and well-being [64]. Individuals constantly seek positive feelings, and in the gaming context, those feelings come as a result of the victory, surpassed challenges and obstacles, grinding, interaction with other players, team bonding, autonomy, sense of belonging, and competence [11], [41].

Although the debate around enjoyment is not a novelty, there are still many uncertainties regarding its definition and psychological roots. Previous studies about entertainment and media describe enjoyment as the satisfaction of needs, while others suggest it is the pursuit of positive feelings [30]. When it comes to the virtual environment, there is a lack of structural cohesion and consensus regarding the theme of enjoyment. Howbeit, it is logical to think that enjoyment is associated with psychological well-being [64].

From another perspective, as a leisure activity, gaming can be perceived as a tool to help alleviate the stress of life and provide amusing moments. More than that, it can be a social activity within the virtual space that aids the players in cultivating temperament and self-development [50], [64]. In spite of the debates whether games are healthy practices, unarguably, it promotes the improvement of cognitive and non-cognitive skills that can be transported to other situations in life [25].

There are, indeed, benefits in incorporating gaming into the daily routine. [64] consider gaming a flourishing practice on mental health capable of improving emotional, social, and psychological well-being. It positively influences players' vitality, resilience, engagement, sense of competence, social connections, and functioning [33]. Naturally, not all games can offer this myriad of benefits, and not all types of players can profit from gaming from a well-being standpoint. Yet, it is safe to assume that, to all players, gaming practices are engaging, motivating, and enjoyable activities worthy of time. Enjoyment is the fundamental principle so, one may add gaming practices as a part of his life. 


\section{GENERAL DISCUSSION}

Studies about lifestyle in the ambit of gaming are still limited, considering that specific theory about the subject has not taken place yet. For this reason, this paper has attempted to provide empirical support for some gaming-related characteristics and practices that could characterize the way of life of online players. Research comprehensively addressing gaming and lifestyle could not be found. Most of the literature focused on specific topics and did not associate lifestyle, consumption, and identity.

\section{A. Theoretical Contributions}

The main theoretical contribution was to explore the idea of a gamer being a hybrid consumer influenced by his life experiences in-game and out-game. Behavioral patterns and consumption choices are all impacted, to some extent, by the trichotomous relationship between the player's personal universe, the game environment, and the tangible reality. In an effort to make such abstraction more intelligible, this paper utilized the concept of lifestyle as a means to express this trichotomy in a more discernible fashion

The player's personal universe, describes the daily activities a gamer undertakes. The option for gaming as a leisure activity, the time he spends playing, the days of the week he chooses to play, with whom the player shares ingame experiences, how much real currency he invests on virtual goods. All of those choices communicate to the world how involved with gaming an individual is. Moreover, habits represent a potential source of people's identity. In other terms, the array of our habits corresponds to fragments of the totality of our true self.

Analogously, habits are routinely manifestations of one's life narrative. This narrative is constantly constructed and revised throughout our lifetime, and by virtue of personal perception, important kept habits tell society part of who we are. It is relevant to underline that some habits, not all, are prone to designate a particular piece of identity. For instance, a gamer who prefers to watch streams instead of playing represents a unique niche of gamers. While he remains a gamer, this particular option for spectating instead of playing distinguishes him even among fellow gamers.

Habits, daily choices, beliefs, and attitudes, when organized, form behavioral patterns objectively connected to lifestyle. As thought, behavioral patterns are also affected by the experience in game environments. Narrative, graphics, aesthetics, characters, conflict, cooperation, challenge, interaction, and reward; all those features have the potential to not only make a game more engaging but to impact a player's worldview. Just like a book, games have the potential to alter an individual's perception and loosen more rigid mental frameworks.

\section{B. Managerial Implications}

Arguably, the most conspicuous managerial implication would be employing the Six Factors as criteria for customer segmentation. Each factor is directly connected to specific consumption practices. Since there is an inventory of information at disposal for decision-makers, managers can more accurately judge how they will interact with gamers, what will be the tone of their communication, how to position or reposition products, and services, what type of content is relevant to their audience, which segment of gamers to target and why gamers choose to adhere to this lifestyle. In brief, this paper offers insightful commentaries that could be useful when formulating marketing promotion strategies, and marketers could profit from products and services within the GLS concept.

\section{LIMITATIONS AND RECOMMENDATIONS FFOR FURTHER WORK}

The main limitation of this research is that, although it was a global survey, there was a preponderance of North American respondents, which means that the results are limited in how representative they can be. Likewise, even though 711 valid returns were received, more responses would have been desired.

On top of that, there are a few recommendations for further study: (1) applying more sophisticated statistical techniques, such as modeling structural equations (SEM) using confirmatory factor analysis (CFA). (2) Developing a more polished GLS scale. (3) Conducting local studies to compare regional differences. (4) Offer new interpretations to the existent factors. (5) Investigate novel factors that could characterize and enrich the GLS concept.

\section{CONCLUSION}

By nature, as an exploratory investigation, this is only a primary step into developing a more consistent and refined GLS theory. Nevertheless, this paper suggests that some lifestyle practices indeed serve a self-expression purpose, and the Six Factors are squarely related to the player's life reality. Even though these variables have different psychological roots, they are somewhat interconnected and adequately correlate to lifestyle constructs. Whereas subtle, at the conclusion of this research, it is possible to perceive that the concept of engagement could be used as an effective way to measure the relationship that each player has with the various factors - possibly leading to new relevant findings.

\section{REFERENCES}

[1] A. Erciş and B. Türk, "Analysis of Virtual Ego in the Virtual World," in The Virtual World and Marketing, 1st ed., London, England: Cambridge Scholars Publishing, 2018, pp. 1-20.

[2] A. Field, "Análise Fatorial Exploratória," in Descobrindo a Estatística usando o SPSS, 2nd ed., Porto Alegre, Brazil: Artmed Editora, 2013, pp. 553-604.

[3] A. Firat, K. Y. Kutucuoğlu, I. A. Saltik, and O. Tuncel, "Consumption, Consumer Culture and Consumer Society," Journal of Community Positive Practice, vol. 13, no. 1, pp. 182-203, 2013.

[4] A. Marchand and T. Hennig-Thurau, "Value Creation in the Video Game Industry: Industry Economics, Consumer Benefits, and Research Opportunities," Journal of Interactive Marketing, vol. 27, no. 3, pp. 141157, Aug. 2013. https://doi.org/10.1016/j.intmar.2013.05.001

[5] B. F. Damásio, "Uses of exploratory factorial analysis in 
psychology," Avaliação Psicológica, vol. 11, no. 2, pp. 213-228, 2012. Available:

http://pepsic.bvsalud.org/scielo.php?script=sci_abstract\&pid=S1677047 $12012000200007 \& \operatorname{lng}=$ t\&\&rm=iso\&tlng=en.

[6] B. Heere, "Embracing the sportification of society: Defining e-sports through a polymorphic view on sport," Sport Management Review, vol. 21, no. 1, pp. 21-24, Jan. 2018. https://doi.org/10.1016/j.smr.2017.07.002

[7] B. Lewis and L. Porter, "In-Game Advertising Effects," Journal of Interactive Advertising, vol. 10, no. 2, pp. 46-60, Mar. 2010. https://doi.org/10.1080/15252019.2010.10722169

[8] B. Simon, "Self and Group in Modern Society: Ten Theses on the Individual Self and the Collective Self ," in The Social Psychology of Stereotyping and Group Life, Oxford, England: Willey-Blackwell, 1997, pp.318-335.

[9] B.-W. Park and K. C. Lee, "Exploring the value of purchasing online game items," Computers in Human Behavior, vol. 27, no. 6, pp. 2178 2185, Nov. 2011. https://doi.org/10.1016/j.chb.2011.06.013

[10] C. A. Scolari, "Transmedia Storytelling: Implicit Consumers, Narrative Worlds, and Branding in Contemporary Media Production," International Journal of Communication, vol. 3, pp. 586-606, 2009.

[11] C. E. Lopez and C. S. Tucker, "The effects of player type on performance: A gamification case study," Computers in Human Behavior, vol. 91, pp. 333-345, Feb. 2019. https://doi.org/10.1016/j.chb.2018.10.005

[12] J. Cleghorn and M.D. Griffiths, "Why do gamers buy 'virtual assets'? An insight in to the psychology behind purchase behaviour,"Digital Education Review, vol.27, pp. 85-104, Jun. 2015. Available: https://files.eric.ed.gov/fulltext/EJ1065003.pdf

[13] D. N. M. Bleize and M. L. Antheunis, "Factors influencing purchase intent in virtual worlds: a review of the literature," Journal of Marketing Communications, vol. 25, no. 4, pp. 403-420, Jan. 2017. https://doi.org/10.1080/13527266.2016.1278028

[14] D. V. Shah, D. M. McLeod, E. Kim, Sun Young Lee, M. R. Gotlieb, S. S. Ho, and H. Breivik, "Political Consumerism: How Communication and Consumption Orientations Drive 'Lifestyle Politics," The ANNALS of the American Academy of Political and Social Science, vol. 611, no. 1, pp. 217-235, May 2007. https://doi.org/10.1177/0002716206298714

[15] D. Vashisht and S. S, "Effects of brand placement strength, prior game playing experience and game involvement on brand recall in advergames," Journal of Indian Business Research, vol. 7, no. 3, pp. 292-312, Aug. 2015. https://doi.org/10.1108/jibr-11-2014-0082

[16] D. Zou, Y. Huang, and H. Xie, "Digital game-based vocabulary learning: where are we and where are we going?," Computer Assisted Language Learning, vol. 34, no. 5-6, pp. 751-777, Jul. 2019. https://doi.org/10.1080/09588221.2019.1640745

[17] E. L. Neely, "Come for the Game, Stay for the Cash Grab: The Ethics of Loot Boxes, Microtransactions, and Freemium Games," Games and Culture, vol. 16, no. 2, pp. 228-247, Nov. 2019. https://doi.org/10.1177/1555412019887658

[18] E. P. Schachter, "Identity Configurations: A New Perspective on Identity Formation in Contemporary Society," Journal of Personality, vol. 72, no. 1, pp. 167-200, Feb. 2004. https://doi.org/10.1111/j.00223506.2004.00260.x

[19] F.-C. Tseng, H.-C. Huang, and C.-I. Teng, "How Do Online Game Communities Retain Gamers? Social Presence and Social Capital Perspectives," Journal of Computer-Mediated Communication, vol. 20, no. 6, pp. 601-614, Nov. 2015. https://doi.org/10.1111/jcc4.12141

[20] F. De Grove, C. Courtois, and J. Van Looy, "How to be a gamer! Exploring personal and social indicators of gamer identity," Journal of Computer-Mediated Communication, vol. 20, no. 3, pp. 346-361, Feb. 2015. https://doi.org/10.1111/jec4.12114

[21] F. De Grove, V. Cauberghe, and J. Van Looy, "In Pursuit of Play: Toward a Social Cognitive Understanding of Determinants of Digital Play," Communication Theory, vol. 24, no. 2, pp. 205-223, Apr. 2014. https://doi.org/10.1111/comt.12030
[22] F. Palmas, R. Reinelt, and G. Klinker, "In-Game Advertising: Brand Integration and Player Involvement as Key Influencing Factors on Brand Recall," HCI in Games: Experience Design and Game Mechanics, pp. 352-367, 2021. https://doi.org/10.1007/978-3-030-77277-2_27

[23] F. Sibilla and T. Mancini, "I am (not) my avatar: A review of the useravatar relationships in Massively Multiplayer Online Worlds," Cyberpsychology: Journal of Psychosocial Research on Cyberspace, vol. 12, no. 3, Dec. 2018. https://doi.org/10.5817/cp2018-3-4

[24] G. Franck, " The economy of attention," Journal of Sociology, vol. 55, no. 1, pp. 8-19, Nov. 2018. https://doi.org/10.1177/1440783318811778

[25] G.-Y. Liao, T. T. L. Pham, T. C. E. Cheng, and C.-I. Teng, "Impacts of real-world need satisfaction on online gamer loyalty: Perspective of selfaffirmation theory," Computers in Human Behavior, vol. 103, pp. 91100, Feb. 2020. https://doi.org/10.1016/j.chb.2019.09.016

[26] H, Aydın. "Virtual Experiential Marketing in the Virtual World," in The Virtual World and Marketing, 1st ed., London, England: Cambridge Scholars Publishing, 2018, pp. 153-168.

[27] H.-C. Huang, T. C. E. Cheng, W.-F. Huang, and C.-I. Teng, "Impact of online gamers' personality traits on interdependence, network convergence, and continuance intention: Perspective of social exchange theory," International Journal of Information Management, vol. 38, no. 1, pp. 232-242, 2018. https://doi.org/10.1016/j.ijinfomgt.2017.08.009

[28] H. Korkeila and J. Hamari, "The Relationship Between Player's Gaming Orientation and Avatar's Capital: a Study in Final Fantasy XIV," Proceedings of the 51st Hawaii International Conference on System Sciences, Jan. 2018, pp. 1893-1902. https://doi.org/10.24251/hicss.2018.239

[29] H. Qin, P. -L. P. Rau, and S. -f. Gao, "The Influence of Social Experience in Online Games," Conference: Proceedings of the 14th international conference on Human-computer interaction: users and applications - Volume Part IV, Jul. 2011, pp. 688-693. https://doi.org/10.1007/978-3-642-21619-0_81

[30] H. Wang, Y. -C. Ruan, S. -Y. Hsu, and C. -T. Sun, " Effects of game design features on player-avatar relationships and motivation for buying decorative virtual items," in DiGRA '19 - Proceedings of the 2019 DiGRA International Conference: Game, Play and the Emerging LudoMix, 2019, pp. 1-22. http://www.digra.org/wp-content/uploads/digitallibrary/DiGRA_2019_paper_161.pdf

[31] J. Huizinga. Homo Ludens: o jogo como elemento da cultura. 4th ed., São Paulo, Brazil: Perspectiva, 2000.

[32] L. F. Rios-Pino, J. E. Mejía-Perea, and E. E. Gallardo-Echenique, "Players Attitudes Towards In-Game Advertising," Information Technology and Systems, pp. 167-176, 2021. https://doi.org/10.1007/978-3-030-68285-9_17

[33] M. B. Oliver, N. D. Bowman, J. K. Woolley, R. Rogers, B. I. Sherrick, and M.-Y. Chung, "Video games as meaningful entertainment experiences.," Psychology of Popular Media Culture, vol. 5, no. 4, pp. 390-405, Oct. 2016. https://doi.org/10.1037/ppm0000066

[34] M. Featherstone, "Lifestyle and Consumer Culture," in Consumer Culture and Postmodernism, pp. 81-92. Available: https://doi.org/10.4135/9781446212424.n6

[35] M. N. Adji, D. Chua, N. Kainama and F. Feranita, "Consumer Preference on Paid Game Microtransaction", Journal of Research in Marketing (JORM - Techmind Research, Canada), vol. 10, no. 3, pp. 832-842, Aug. $2019 . \quad$ Available: https://core.ac.uk/download/pdf/229163936.pdf

[36] M. R. Johnson and J. Woodcock, "The impacts of live streaming and Twitch.tv on the video game industry," Media, Culture \& Society, vol. 41, no. 5, pp. 670-688, Dec. 2018. https://doi.org/10.1177/0163443718818363

[37] M. Sjöblom and J. Hamari, "Why do people watch others play video games? An empirical study on the motivations of Twitch users," Computers in Human Behavior, vol. 75, pp. 985-996, Oct. 2017. https://doi.org/10.1016/j.chb.2016.10.019

[38] M. Sjöblom, M. Törhönen, J. Hamari, and J. Macey, "The ingredients of Twitch streaming: Affordances of game streams," Computers in Human 
Behavior, vol. 92, pp. 20-28, Mar. 2019. https://doi.org/10.1016/j.chb.2018.10.012

[39] M. T. Payne, "Connected Viewing, Connected Capital: Fostering Gameplay Across Screens" in Connected viewing: selling, streaming \& sharing media in the digital era, 1st ed., New York, United States of America: Routledge, 2013.

[40] M. W. Watkins, "Exploratory Factor Analysis: A Guide to Best Practice," Journal of Black Psychology, vol. 44, no. 3, pp. 219-246, Apr. 2018. https://doi.org/10.1177/0095798418771807

[41] N. H. M. Zain, M. H. Hashim, A. Baharum, I. Ismail, R. A. Aziz, and A. M. Yasin, "Evaluating Player Enjoyment in Mobile Games," Advanced Science Letters, vol. 24, no. 2, pp. 1366-1369, Feb. 2018. https://doi.org/10.1166/asl.2018.10751

[42] P. Joe and N. Malhotra, "An exploratory study on increase of transactions with the use of deferred payment facilities," SMART Journal of Business Management Studies, vol. 17, no. 1, pp. 11-19, 2021. https://doi.org/10.5958/2321-2012.2021.00002.6

[43] P. Simonson, J. Morooka, B. Xiong, and N. Bedsole, "The Beginnings of Mass Communication: A Transnational History," Journal of Communication, vol. 69, no. 5, pp. 513-538, Oct. 2019. https://doi.org/10.1093/joc/jqz027

[44] R. Kowert, R. Festl, and T. Quandt, "Unpopular, Overweight, and Socially Inept: Reconsidering the Stereotype of Online Gamers," Cyberpsychology, Behavior, and Social Networking, vol. 17, no. 3, pp. 141-146, Mar. 2014. https://doi.org/10.1089/cyber.2013.0118

[45] R. de O. Santos, B. M. Gorgulho, M. A. de Castro, R. M. Fisberg, D. M. Marchioni, and V. T. Baltar, "Principal Component Analysis and Factor Analysis: differences and similarities in Nutritional Epidemiology application," Revista Brasileira de Epidemiologia, vol. 22, 2019. https://doi.org/10.1590/1980-549720190041

[46] R. Tukachinsky and G. Stever, "Theorizing Development of Parasocial Engagement," Communication Theory, vol. 29, no. 3, pp. 209-230, Dec. 2018. https://doi.org/10.1093/ct/qty032

[47] S. Sawyer, "Oh Me, Oh My! Identity Development Through Video Games," in Video Games and Well-being, Palgrave Pivot, 2019, pp. 4963. https://doi.org/10.1007/978-3-030-32770-5_4

[48] S.T. Poon, "Designing Brand Culture Based on the Advertising's New Medium of Human Experience: Integrating the Application in Lifestyle Retailing Strategy," International Journal of Media, Journalism and Mass Communications, vol. 2, no. 2, pp. 8-15, 2016. https://doi.org/10.20431/2454-9479.0202007

[49] S. Thomas and C. S. Kohli, "Can brand image move upwards after Sideways? A strategic approach to brand placements," Business Horizons, vol. 54, no. 1, pp. 41-49, Jan. 2011. https://doi.org/10.1016/j.bushor.2010.08.002

[50] S. Trepte and L. Reinecke, "The Pleasures of Success: Game-Related Efficacy Experiences as a Mediator Between Player Performance and Game Enjoyment," Cyberpsychology, Behavior, and Social Networking, vol. 14, no. 9, pp. 555-557, Sep. 2011. https://doi.org/10.1027/1864$1105 / \mathrm{a} 000022$

[51] S. Trepte and L. Reinecke, "Avatar Creation and Video Game Enjoyment," Journal of Media Psychology, vol. 22, no. 4, pp. 171-184, Jan. 2010. https://doi.org/10.1027/1864-1105/a000022
[52] S. Ünal, T. Dalgı̣ and E. Akar, "Avatars as the Virtual World's Personality" in The Virtual World and Marketing, 1st Edition. London, England: Cambridge Scholars Publishing, 2018, pp. 33-54.

[53] S. You, E. Kim, and D. Lee, "Virtually Real," Games and Culture, vol. 12, no. 1, pp. 56-71, May 2016. https://doi.org/10.1177/1555412015581087

[54] T. A. Putra, B. Hayat, and R. Latifa, "Why Do We Buy Virtual Goods?," 2019 7th International Conference on Cyber and IT Service Management (CITSM), Nov. 2019, pp.1-4. https://doi.org/10.1109/citsm47753.2019.8965331

[55] T.-A. Wilska, "Me-a consumer? consumption, identities and lifestyles in today's Finland," Acta Sociologica, vol. 45, no. 3, pp. 195-210, 2002. https://doi.org/10.1177/000169930204500302

[56] T. Inoue and I. Yoshitake, "Simple Prediction Formula for Proportion Installment Interest Rate in a Private Finance Initiative Project," Journal of Service Science and Management, vol. 06, no. 03, pp. 206-210, 2013. https://doi.org/10.4236/jssm.2013.63022

[57] T. Wulf, F. M. Schneider, and S. Beckert, "Watching Players: An Exploration of Media Enjoyment on Twitch," Games and Culture, vol. 15, no. 3, pp. 328-346, Jul. 2018. https://doi.org/10.1177/1555412018788161

[58] X. Lin, W. Su, and M. N. Potenza, "Development of an Online and Offline Integration Hypothesis for Healthy Internet Use: Theory and Preliminary Evidence," Frontiers in Psychology, vol. 9, Jan. 2019. https://doi.org/10.3389/fpsyg.2019.00106

[59] X. Wang, A. H. Butt, Q. Zhang, N. Shafique, and H. Ahmad, “'Celebrity Avatar' Feasting on In-Game Items: A Gamers' Play Arena," SAGE Open, vol. 11, no. 2, p. 215824402110157, Apr. 2021. https://doi.org/10.1177/21582440211015716

[60] X. Zhang and V. Savalei, "Improving the Factor Structure of Psychological Scales," Educational and Psychological Measurement, vol. 76, no. 3, pp. 357-386, Jul. 2015. https://doi.org/10.1177/0013164415596421

[61] W. Cai, M. Chen, and V. C. M. Leung, "Toward Gaming as a Service," IEEE Internet Computing, vol. 18, no. 3, pp. 12-18, May 2014. https://doi.org/10.1109/mic.2014.22

[62] W. Peng and G. Hsieh, "The influence of competition, cooperation, and player relationship in a motor performance centered computer game," Computers in Human Behavior, vol. 28, no. 6, pp. 2100-2106, Nov. 2012. https://doi.org/10.1016/j.chb.2012.06.014

[63] W. Tina and K. Buckner, "Receptiveness of Gamers to Embedded Brand Messages in Advergames," Journal of Interactive Advertising, vol. 7, no. 1, $\quad$ pp. $3-32, \quad 3006$. https://doi.org/10.1080/15252019.2006.10722123

[64] Y. J. Halbrook, A. T. O’Donnell, and R. M. Msetfi, "When and How Video Games Can Be Good: A Review of the Positive Effects of Video Games on Well-Being," Perspectives on Psychological Science, vol. 14, no. 6, pp. 1096-1104, Nov. 2019. https://doi.org/10.1177/1745691619863807 